OPEN ACCESS

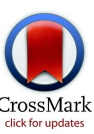

Research, University of

Liverpool and Liverpool

Women's Hospital, Liverpool L8

7SS, UK

2School of Social and

Community Medicine, University

of Bristol, Bristol BS8 2PS, UK

Correspondence to:

Z Alfirevic zarko@liv.ac.uk

Additional material is published online only. To view please visit the journal online (http:// dx.doi.org/10.1136/BMJ.h217)

Cite this as: $B M J$ 2015;350:h217 doi: 10.1136/bmj.h217

Accepted: 08 December 2014
${ }^{1}$ Centre for Women's Health

\section{Labour induction with prostaglandins: a systematic review and network meta-analysis}

\author{
Zarko Alfirevic, ${ }^{1}$ Edna Keeney, ${ }^{2}$ Therese Dowswell, ${ }^{1}$ Nicky J Welton, ${ }^{2}$ Sofia Dias, ${ }^{2}$ Leanne V Jones, ${ }^{1}$ \\ Kate Navaratnam, ${ }^{1}$ Deborah M Caldwell, ${ }^{2}$
}

\author{
ABSTRACT \\ OBJECTIVES \\ To assess the effectiveness and safety of \\ prostaglandins used for labour induction. \\ DESIGN \\ Systematic review with Bayesian network meta- \\ analysis
}

\section{DATA SOURCES}

The Cochrane Pregnancy and Childbirth Group's Database of Trials (which incorporates the results of a broad generic search for all pregnancy and postpartum trials). Sources included are CENTRAL, Medline, Embase, NHS Economic Evaluation Database, CINAHL, relevant journals, conference proceedings, and registries of ongoing trials.

\section{ELIGIBILITY CRITERIA FOR SELECTING STUDIES \\ Randomised clinical trials of prostaglandin or prostaglandin analogues used for third trimester cervical ripening or labour induction versus placebo or no treatment, alternative prostaglandin dose or administration, or a different type of prostaglandin. We included studies recruiting women with a viable fetus, but had no other restrictions relating to indication for labour induction or language of publication. Outcomes assessed were serious neonatal morbidity (trialist defined) or perinatal death; serious maternal morbidity (trialist defined) or death; vaginal delivery not achieved within 24 hours, caesarean section, and uterine hyperstimulation with fetal heart rate changes. RESULTS \\ 280 randomised clinical trials were included (48 068 women) in the review. Maternal and neonatal mortality and serious morbidity were rarely reported and are summarized narratively. Unresolved inconsistency was observed for the hyperstimulation outcome. Relative}

\section{WHAT IS ALREADY KNOWN ON THIS TOPIC}

Labour inductions have increased steadily worldwide, with overall rates in many countries now exceeding $20 \%$ of all births

Many methods have been tested, but prostaglandins remain a preferred method for cervical ripening and labour induction

Informal indirect comparisons between different protocols for labour induction may lead to incorrect conclusions, and there is therefore a need to synthesize relevant evidence in a coherent manner

\section{WHAT THIS STUDY ADDS}

This network meta-analysis finds that misoprostol may be the best prostaglandin for labour induction

Titrated low dose oral solution seems to be the safest in terms of risk of caesarean section, while vaginal misoprostol tablets $(\geq 50 \mu \mathrm{g})$ are the most effective in achieving vaginal delivery within 24 hours of induction to placebo, the odds of failing to achieve a vaginal delivery were lowest for vaginal misoprostol $(\geq 50 \mu \mathrm{g})$ (odds ratio 0.06 (95\% credible interval 0.02 to 0.12 )), with a $39 \%$ absolute probability of event $(95 \%$ credible interval $1 \%$ to $94 \%$ ). Compared with placebo, odds of caesarean section were lowest for titrated oral misoprostol solution $(<50 \mu \mathrm{g})$ (odds ratio $0.65(0.49$ to 0.83$)$ ), with an absolute probability of event of $15 \%$ (3\% to $40 \%$ ).

\section{CONCLUSIONS}

Low dose $(<50 \mu \mathrm{g})$ titrated oral misoprostol solution had the lowest probability of caesarean section, whereas vaginal misprostol ( $\geq 50 \mu \mathrm{g})$ had the highest probability of achieving a vaginal delivery within 24 hours. These findings have important implications for a series of current national and international guidelines for induction of labour and future research in this area.

\section{SYSTEMATIC REVIEW REGISTRATION} PROSPERO 2013:CRD42013005116

\section{Introduction}

Labour inductions have increased steadily over the past two decades, with overall rates in many countries now exceeding 20\% of all births. ${ }^{12}$ Many different methods have been used, but prostaglandins remain a preferred method for cervical ripening and labour induction. ${ }^{1} 34$ Although various prostaglandins have been tested in randomised trials, current recommendations have not been based on a quantitative overview of the accumulated evidence of their effectiveness and safety. Published meta-analyses have focused on pairwise "head to head" comparisons, ${ }^{5-7}$ but clinicians, women, and policy makers tend to make informal indirect comparisons between different methods. Such an informal approach may lead to incorrect and incoherent conclusions, and there is, therefore, a need to synthesize evidence in a coherent manner. ${ }^{8}$

Network meta-analysis (also known as multiple treatment meta-analysis or mixed-treatment comparisons) allows a formal solution to this issue, preserving the randomized nature of the evidence. A network meta-analysis is the simultaneous comparison of multiple competing treatments in a single statistical model and is increasingly used in comparative effectiveness research. ${ }^{9}$ The methodology has been available for some time ${ }^{10} 11$ and is internationally recognized by health technology assessment organizations ${ }^{12} 13$ and the Cochrane Collaboration. ${ }^{14}$ Network meta-analysis has been applied across clinical areas as diverse as obstetrics, ${ }^{15}$ cardiology, ${ }^{16}$ psychiatry, ${ }^{17}{ }^{18}$ rheumatology, ${ }^{19}$ and surgery ${ }^{20}$ among others. By exploiting all the available 
evidence, both direct and indirect, a network meta-analysis produces estimates of the relative effects of each treatment compared with all others in the network, even if not all treatments have been directly compared with each other. It is then possible to calculate the probability of one treatment being the best for a specific outcome; in this way different treatment options can be ranked from best to worst for each outcome.

In this paper we present a network meta-analysis to quantify the effects and safety of different prostaglandins used for labour induction. Originally conceived as a standalone investigation, it is now also part of a larger project looking at all methods for labour induction (PROSPERO 2013:CRD42013005116).

\section{Methods}

\section{Search strategy and selection criteria}

To identify potentially eligible trials, we searched the Cochrane Pregnancy and Childbirth Group's Database of Trials (which incorporates the results of a broad generic search for all pregnancy and postpartum trials). Sources searched were CENTRAL, Medline, Embase, NHS Economic Evaluation Database, CINAHL, relevant journals, conference proceedings, and registries of ongoing trials. The full text of every relevant trial report was obtained and assigned to a topic depending on the intervention before adding to the database. This approach leads to a more specific search. We then screened all reports assigned to the "induction of labour" topic. The detailed search strategy, along with references for all reports identified by the search, are in appendices 1-3. Information relating to the characteristics of the included studies and different doses and regimens used are outlined in appendices 4 and 5. The latest search was completed in March 2014.

We included all randomised clinical trials comparing a prostaglandin or prostaglandin analogue used for third trimester cervical ripening or labour induction with placebo or no treatment, with the same prostaglandin administered by a different route or dose, or with a different type of prostaglandin. We included only studies recruiting women with a viable fetus but had no other restrictions relating to indication for labour induction, language, or date of publication.

We included 12 different types of prostaglandin or prostaglandin analogue: vaginal prostaglandin $\mathrm{E}_{2}$ as tablets, gel, pessary, or sustained release pessary; intracervical prostaglandin $\mathrm{E}_{2}$; prostaglandin $\mathrm{F} 2 \mathrm{a}$ gel; vaginal misoprostol tablet (dose $<50 \mu \mathrm{g}$ or $\geq 50 \mu \mathrm{g}$ ) or sustained release pessary; oral misoprostol tablet (dose $<50 \mu \mathrm{g}$ or $\geq 50 \mu \mathrm{g}$ ); and oral misoprostol solution $(<50 \mu \mathrm{g})$. Intravenous prostaglandins, oral prostaglan$\operatorname{din} E_{2}$, and buccal prostaglandin $E_{2}$ were excluded since these routes of administration are rarely used in clinical practice.

Each preparation was examined separately as different routes of administration and doses may be associated with differential effects. Trials were eligible for inclusion if they compared two or more of these active agents or were compared an active agent with placebo or no treatment (fig 1). Treatment arms were categorized according to the initial randomized allocation, although subsequent clinical management may have included further doses or an alternative treatment.

\section{Data extraction and assessment of risk of bias}

Five reviewers extracted data from the trial reports using a specifically designed form capturing information on study design, trial setting, patient characteristics, prostaglandin type and dose, and outcomes. All reports were read by two reviewers, and disagreement was resolved by joint review of the manuscript to reach consensus. Our analysis was restricted to five key outcomes in terms of effectiveness and safety, identified as such by the Cochrane Pregnancy and Childbirth Group:21 22

- Serious neonatal morbidity (trialist defined) or perinatal death

- Serious maternal morbidity (trialist defined) or death

- Vaginal delivery not achieved within 24 hours

- Caesarean section (any indication)

- Uterine hyperstimulation with fetal heart rate changes.

Study quality was assessed using the methods described in the Cochrane Handbook. ${ }^{23}$ For use in a pre-specified sensitivity analysis, we assigned a judgment relating to risk of bias (low, high, unclear) based on the allocation concealment domain. We based this decision on meta-epidemiological evidence regarding sources of bias and design of obstetric trials. ${ }^{24}$

An important assumption underpinning network meta-analysis is that there is consistency between the direct and indirect evidence; that is, that the direct and indirect estimates of relative treatment effect are similar. Consistency may be undermined if there is an imbalance in effect modifiers across treatment comparisons. We therefore pre-specified and extracted information on potential key effect modifiers-that is, gestational age, parity, previous caesarean section, Bishop score, and status of amniotic membranes (intact or ruptured). We visually assessed whether the effect modifiers were similarly distributed across trials, through cross-tabulations.

\section{Data synthesis and statistical analysis}

A network meta-analysis was conducted to simultaneously compare the 12 prostaglandin treatments and placebo or no treatment for each outcome. In its simplest form, a network meta-analysis is the combination of direct and indirect estimates of relative treatment effect in a single analysis. An indirect estimate of the relative treatment effect $A$ versus $B$ can be formed by comparing direct trials of $A$ versus $C$ with trials of $B$ versus $C$. A simple approach to combining the indirect and direct estimates of A versus B would be to take a weighted average, for example using an inverse variance weighting. ${ }^{25}$

All analyses were conducted within a Bayesian framework using OpenBUGS. ${ }^{26}$ Where direct data were available, pairwise meta-analyses were also performed and compared with the network meta-analysis 
treatment effect estimates to informally assess agreement. Studies with 0 or $100 \%$ events in all arms were excluded from the analysis because these studies provide no evidence on relative effects. ${ }^{27}$ For studies with a 0 or $100 \%$ events in one arm only, we planned to analyze the data without continuity corrections where computationally possible. To avoid double counting of events, multi-arm trials were analysed in their original form without the need to combine treatment arms.

Both fixed and random effects models (accounting for the correlations induced between trial-specific effects in multi-arm trials) were considered on the basis of model fit. Goodness of fit was measured using the posterior mean of the residual deviance, the degree of between-study heterogeneity, and the deviance information criterion. In a well fitting model the posterior mean residual deviance should be close to the number of data points. ${ }^{28} 29$ Heterogeneity was reported as the posterior median between-trial standard deviation $(\tau)$ with its $95 \%$ credible interval. Differences of $\geq 5$ points for deviance information criterion were considered meaningful. ${ }^{28}$

Consistency between the different sources of evidence was explored statistically by comparing the fit of a model assuming consistency with a model which allowed for inconsistency. ${ }^{30}$ If the inconsistency model had the smallest posterior mean residual deviance, heterogeneity, or deviance information criterion value then this indicates potential inconsistency in the data. Where model fit was indicative of inconsistency, we firstly planned to restrict analysis to those trials with adequate allocation concealment. If this did not resolve apparent inconsistency we planned further subgroup analyses using potential treatment effect modifiers identified as being unevenly distributed across the treatments. The impact of removing placebo and no-treatment nodes from the network was also examined in sensitivity analyses, because of the possibility that such trials may have included lower risk populations than head-to-head comparisons of active treatments.

Full details of priors and convergence checks are given in appendix 7, but they are briefly summarized here. Vague prior distributions were specified for treatment effect and heterogeneity parameters. Convergence was assessed using the Brooks-Gelman-Rubin diagnostic plots 334 and was satisfactory by 90000 simulations for all outcomes. A further simulation sample of at least 180000 iterations post-convergence was obtained on which all reported results were based.

Relative treatment effects are reported as posterior median odds ratios and 95\% credible intervals. We calculated the probability of each treatment being first, second, third, etc, most effective for each outcome. As this metric can be unstable, the posterior median of the ranking of each treatment (and 95\% credible intervals) are also reported, with the convention that the lower the rank the better the treatment. The absolute probability of an event on each treatment was also calculated by applying the log odds ratios to the log odds estimated from a synthesis of reference treatment (placebo) arms. ${ }^{27}$ We used this to inform the calculation of the number needed to treat to harm (all events considered here are undesirable). For the interested reader, posterior median risk ratios are also reported in appendix 6 (table 16).

\section{Results}

The search identified 540 studies (708 reports) potentially eligible for inclusion in the review. Of these, 260 studies were excluded (see fig 1 for reasons for exclusion). We included 280 studies in the systematic review, and data were available for at least one of our outcomes for 48068 women. The data used in the analyses are reported in appendix 6 (tables 10-14).

The complete comparison networks-including 280 randomised controlled trials of prostaglandins examining 12 different regimens, no treatment, and placebo-are presented in figure 2 for failure to achieve vaginal delivery in 24 hours, caesarean section, uterine hyperstimulation, serious neonatal morbidity or perinatal death, and serious maternal morbidity or death. ${ }^{35}$

\section{Vaginal delivery not achieved within 24-hours}

After the exclusion of trials with zero events in all arms, 94 trials were available for network analysis. There were no trials remaining that compared prostaglandin $F_{2}$. Meaningful differences were observed in posterior mean residual deviance and deviance information

Studies identified through searching Cochrane Pregnany and Childbirth Group database of trials ( $n=540 ; 708$ reports)

Excluded from systematic review ( $\mathrm{n}=260 ; 287$ reports): Not a randomised controlled trial $(n=27)$ No relevant outcome data $(n=70)$

$\rightarrow$ Not a relevant comparison $(n=114)$

Not a relevant participant group $(n=9)$

Methodological issues $(n=13)$ Insufficient information $(\mathrm{n}=27)$

No of arms relating to different treatments $(n=574)$ :

No treatment $(n=31)$

Placebo $(n=61)$

Vaginal prostaglandin $E_{2}$ tablet $(n=32$

Vaginal prostaglandin $E_{2}$ gel $(n=74)$

Vaginal prostaglandin $E_{2}$ pessary (slow release) $(n=35)$

Prostaglandin $F_{2}$ gel $(n=5)$

Intracervical prostaglandin $E_{2}(n=101)$

Vaginal prostaglandin $E_{2}$ pessary (normal release) $(n=19)$

Vaginal misoprostol (dose $<50 \mu \mathrm{g})(n=55)$

Vaginal misoprostol (dose $\geq 50 \mu \mathrm{g})(\mathrm{n}=92)$

Oral misoprostol (dose $<50 \mu \mathrm{g})(\mathrm{n}=3)$

Oral misoprostol (dose $\geq 50 \mu \mathrm{g})(\mathrm{n}=55)$

Low dose misoprostol solution $(n=9)$

Sustained release misoprostol $(n=2)$

This includes 267 two-arm trials, 12 three-arm trials, and 1 four-arm trial

Excluded from network meta-analysis $(n=195)$ :

Caesarean section analysis $(n=11)$ :

Did not report outcome $(n=8)$

Had $0 \%$ or $100 \%$ rate event on each arm $(n=3)$

Vaginal delivery analysis $(n=187)$

Did not report outcome $(n=186)$

Had $100 \%$ event rate on each arm $(n=1)$

Fig 1 | Prisma diagram of study selection for network meta-analysis 


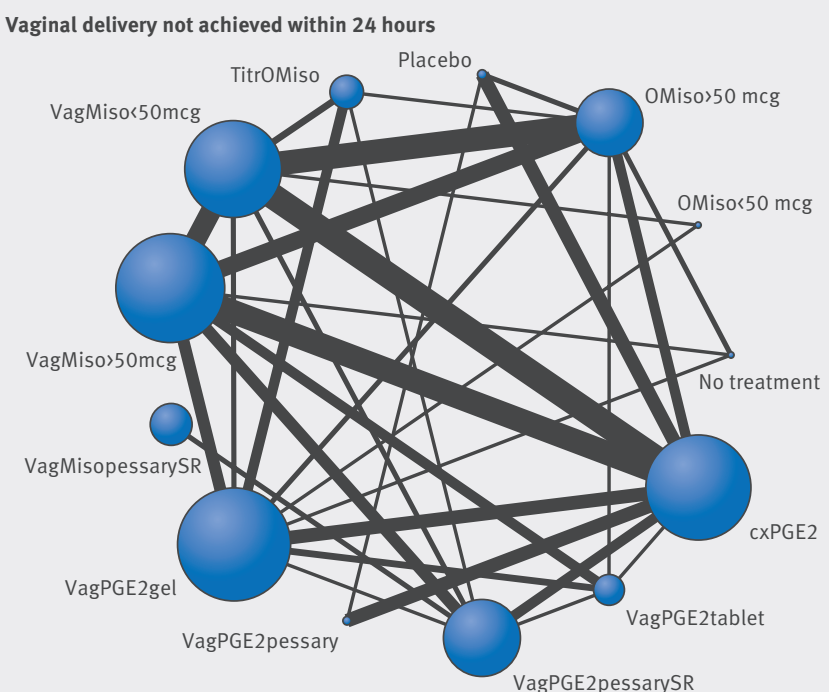

Uterine hyperstimulation

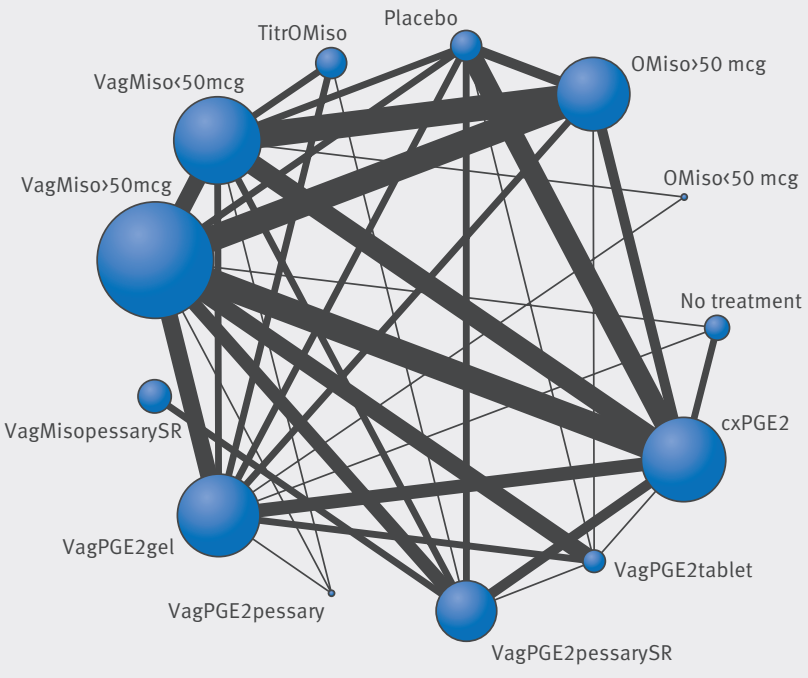

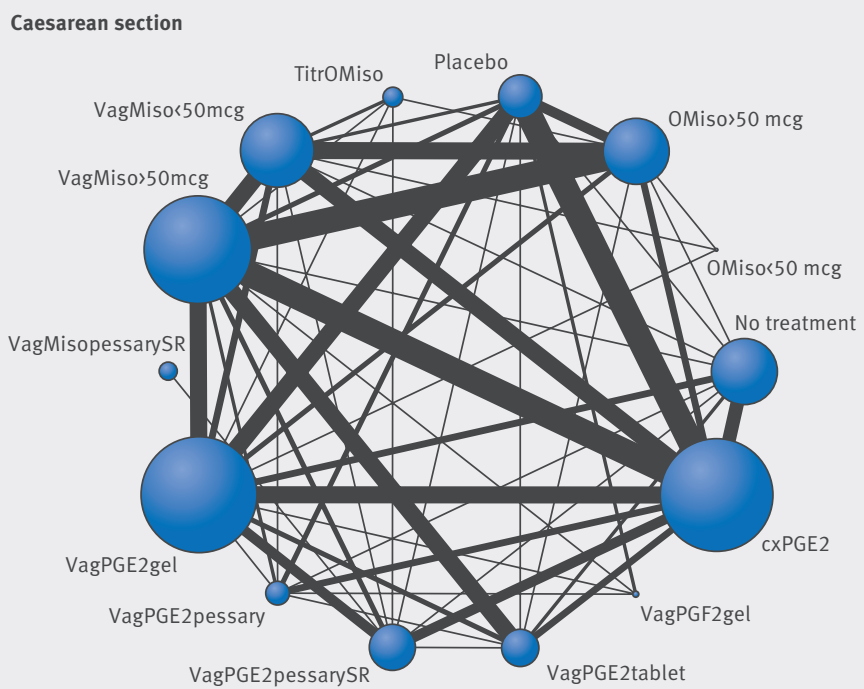

Serious neonatal morbidity or perinatal death

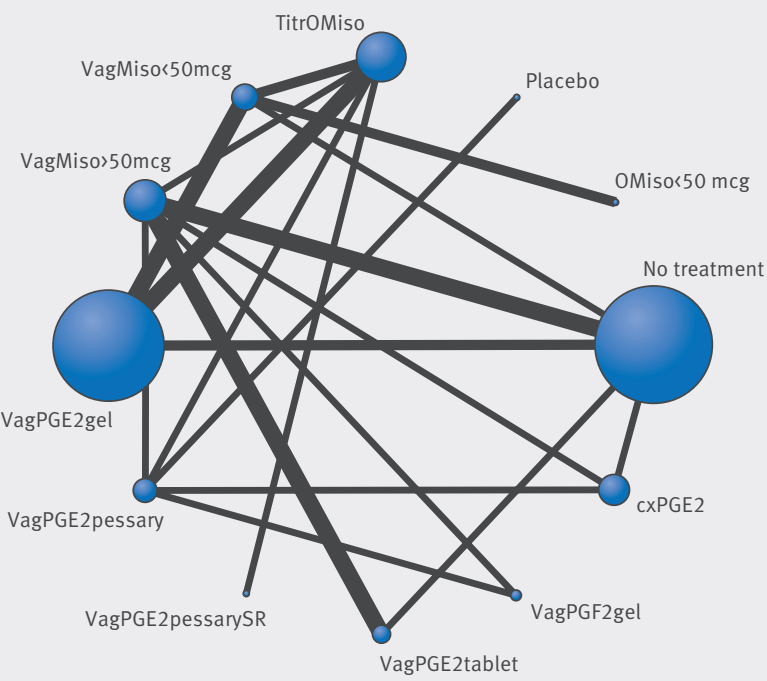

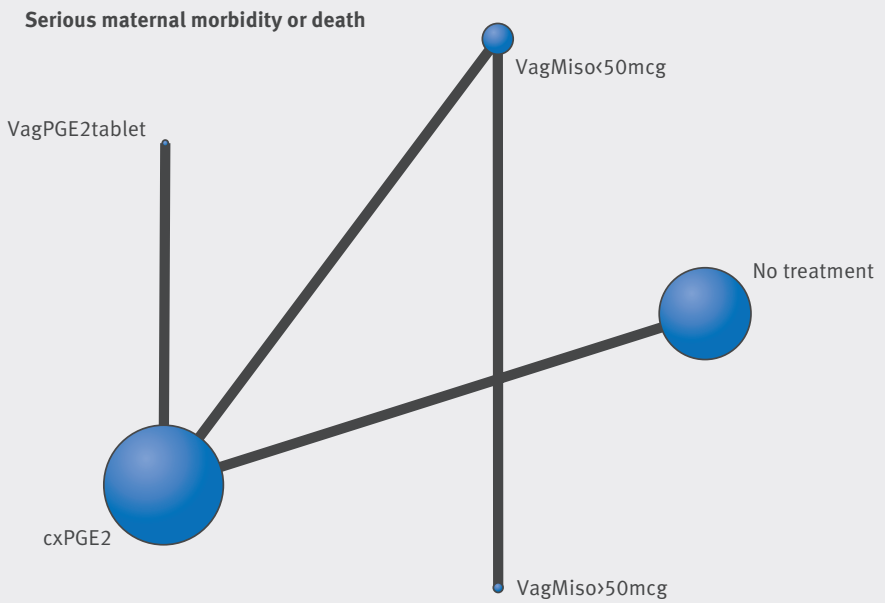

VagPGE2tablet $=$ Vaginal prostaglandin $E_{2}$ tablet; VagPGE2gel = Vaginal prostaglandin $E_{2}$ gel; VagPGE2 pessarySR $=$ Vaginal prostaglandin $E_{2}$ pessary (slow release); CXPGE2 = Intracervical prostaglandin $\mathrm{E}_{2}$; VagPGE2pessary = Vaginal prostaglandin $\mathrm{E}_{2}$ pessary (normal release); VagPGF gel = Vaginal prostaglandin $\mathrm{F}_{2}$ gel;

VagMiso $<50 \mathrm{mcg}=$ Vaginal misoprostol (dose $<50 \mu \mathrm{g}) ;$ VagMiso $>50 \mathrm{mcg}=$ Vaginal misoprostol (dose $\geq 50 \mu \mathrm{g}) ; 0$ Miso $<50 \mathrm{mcg}=0$ ral misoprostol tablet (dose $<50 \mu \mathrm{g})$;

OMiso $>50 \mathrm{mcg}=$ Oral misoprostol tablet (dose $\geq 50 \mu \mathrm{g}$ ); TitrOMiso $=$ Titrated (low dose) oral misoprostol solution; VagMisopessarySR $=$ Vaginal misoprostol pessary

(slow release)

Fig 2 Networks of eligible comparisons for five outcomes: vaginal delivery not achieved within 24 hours, caesarean section, uterine hyperstimulation, serious neonatal morbidity or perinatal death, and serious maternal morbidity or death. The width of the lines is proportional to the number of trials comparing each pair of treatments, and the size of each node is proportional to the number of randomised participants (sample size) 
criterion values, suggesting that, for the full network, the inconsistency model is preferred over the consistency model (appendix 6, table 7). To explore the source of the observed inconsistency, we conducted a pre-specified sensitivity analysis examining the effect of removing trials at high risk of bias from the network. The random effects model, excluding these trials, provided an adequate fit to the data (appendix 6, table 7), and reported results are based on this model, with 64 trials (Table 1, and fig 3).

Despite the observation of high between-trials heterogeneity ( $\tau=0.47$ ( $95 \%$ credible interval 0.34 to 0.63 )) (relative to the size of the treatment effect estimates as measured on the log odds scale), there was strong evidence that all prostaglandins increased the odds of achieving a vaginal birth within 24 hours when compared with placebo (Table 1). When active treatments were compared, 14 out of 55 comparisons reached conventional level of statistical significance (fig 3). The absolute probabilities of failing to achieve a vaginal birth within 24 hours are shown in table 1 , alongside the odds ratios relative to placebo. We note that the absolute probability of an event for vaginal misoprostol tablet $\geq 50 \mu$ g was $39 \%$ (95\% credible interval $1 \%$ to $94 \%$ ), closely followed by that for titrated (low dose) oral misoprostol solution ( $41 \%$ probability (2\% to $95 \%$ )).

Figure 4 shows the distribution of the rankings for each of the 12 prostaglandin treatments. The $\mathrm{x}$ axis reports each of the possible 12 ranks, where position 1 means the treatment is ranked the highest and position 12 the lowest. The y axis shows the probability with which each treatment has been ranked at each of the 12 possible positions and therefore fully encapsulates the uncertainty in the treatment rankings. For example, consider vaginal prostaglandin $\mathrm{E}_{2}$ tablet in the top left-hand corner of the figure. For the outcome achieving vaginal delivery within 24 hours of induction, the probability of vaginal prostaglandin $\mathrm{E}_{2}$ tablet being ranked first is $5 \%$, the probability of being ranked second is around $10 \%$, peaking at a $15 \%$ probability of being ranked sixth. We can conclude from figure 4 that there is considerable uncertainty in the estimation of any rank for vaginal prostaglandin $\mathrm{E}_{2}$ tablet. Note that this uncertainty is also reflected in the credible interval around the median rank, which spans from 1st to 9th "best" treatment for this outcome.

The best treatment for achieving a vaginal birth within 24 hours was vaginal misoprostol tablet $\geq 50 \mu$ g, with a probability of being best of $53 \%$. The probability of being ranked in the top three treatments was $97 \%$ for vaginal misoprostol tablet $\geq 50 \mu \mathrm{g}$ and $73 \%$ for titrated (low dose) oral misoprostol solution. The remaining treatments all rated lower than a $40 \%$ probability of being in the top three treatments. The probability of being ranked in the bottom three (that is, poorest in terms of achieving a vaginal birth within 24 hours) was $92 \%$ for vaginal prostaglandin $\mathrm{E}_{2}$ pessary (normal release), $80 \%$ for oral misoprostol $<50 \mu$ g, and $67 \%$ for intracervical prostaglandin $\mathrm{E}_{2}$.

\section{Caesarean section}

After the exclusion of trials with zero or $100 \%$ events in all arms, 269 trials were available for inclusion in both the pairwise and network meta-analyses (fig 2). The 95\% credible intervals from the direct and network meta-analysis random effects analyses were overlapping. However, for comparability with the results for the vaginal delivery outcome, the results we report here are those from the random effects sensitivity analysis, having removed trials at high risk of bias (160 trials

\begin{tabular}{|c|c|c|c|c|}
\hline \multirow[b]{2}{*}{ Treatment comparison } & \multirow{2}{*}{$\begin{array}{l}\text { Direct } \\
\text { comparison } \\
\text { Odds ratio } \\
(95 \% \mathrm{Crl})^{\star}\end{array}$} & \multicolumn{3}{|c|}{ Network meta-analysis } \\
\hline & & $\begin{array}{l}\text { Odds ratio } \\
(95 \% \mathrm{Crl})^{\star}\end{array}$ & NNT $(95 \% \mathrm{Crl}) \dagger$ & $\begin{array}{l}\text { Absolute } \\
\text { probability } \\
(95 \% \mathrm{Crl})\end{array}$ \\
\hline Placebo & Reference & Reference & Reference & $0.81(0.23$ to 1.00$)$ \\
\hline No treatment & - & $0.32(0.09$ to 1.14$)$ & $7(-49$ to 285$)$ & $0.66(0.07$ to 0.99$)$ \\
\hline Vaginal prostaglandin $\mathrm{E}_{2}$ (tablet) & - & $0.08(0.03$ to 0.20$)$ & $3(2$ to 31$)$ & $0.45(0.02$ to 0.96$)$ \\
\hline Vaginal prostaglandin $\mathrm{E}_{2}$ (gel) & - & $0.08(0.03$ to 0.17$)$ & $2(2$ to 27$)$ & $0.44(0.02$ to 0.96$)$ \\
\hline Vaginal prostaglandin $\mathrm{E}_{2}$ pessary (slow release) & - & $0.10(0.04$ to 0.24$)$ & $3(2$ to 37$)$ & $0.48(0.03$ to 0.97$)$ \\
\hline Prostaglandin $\mathrm{F}_{2}$ gel & Not in network & Not in network & Not in network & Not in network \\
\hline Intracervical prostaglandin E2 & 0.09 (0.03 to 0.24$)$ & $0.12(0.06$ to 0.26$)$ & $3(2$ to 46$)$ & $0.52(0.03$ to 0.97$)$ \\
\hline Vaginal prostaglandin $E_{2}$ pessary (normal release) & 0.46 (0.07 to 3.09) & 0.19 (0.07 to 0.52$)$ & $5(2$ to 92$)$ & 0.59 (0.05 to 0.98$)$ \\
\hline Vaginal misoprostol $(<50 \mu \mathrm{g})$ & - & $0.07(0.03$ to 0.16$)$ & $2(2$ to 26$)$ & $0.43(0.02$ to 0.96$)$ \\
\hline Vaginal misoprostol $(\geq 50 \mu \mathrm{g})$ & - & $0.06(0.02$ to 0.12$)$ & $2(1$ to 20$)$ & 0.39 (0.01 to 0.94) \\
\hline Oral misoprostol tablet $(<50 \mu \mathrm{g})$ & - & $0.16(0.05$ to 0.48$)$ & $4(2$ to 77$)$ & $0.56(0.04$ to 0.98$)$ \\
\hline Oral misoprostol tablet $(\geq 50 \mu \mathrm{g})$ & $0.10(0.03$ to 0.31$)$ & $0.08(0.04$ to 0.18$)$ & $3(2$ to 30$)$ & $0.46(0.02$ to 0.96$)$ \\
\hline Titrated oral misoprostol solution $(<50 \mu \mathrm{g})$ & - & $0.06(0.03$ to 0.15$)$ & 2 (1 to 23$)$ & $0.41(0.02$ to 0.95$)$ \\
\hline Misoprostol vaginal pessary sustained release & - & 0.09 (0.03 to 0.35) & $3(1$ to 43$)$ & $0.47(0.02$ to 0.97$)$ \\
\hline \multicolumn{5}{|c|}{$\begin{array}{l}95 \% \mathrm{Crl}=95 \% \text { credible interval. NNT = number needed to treat. } \\
\text { *An odds ratio }>1 \text { favours placebo (that is, fewer events occur with placebo than with active treatment), whereas an odds ratio }<1 \text { favours active } \\
\text { treatment (fewer undesirable events occur with active treatment). Empty cells indicate that no direct evidence was available for that comparison. } \\
\text { tNNTs were calculated based on the absolute odds of an event on the reference treatment. Positive NNTs are interpreted as the number of women } \\
\text { needed to be treated to prevent one failure to achieve vaginal delivery within } 24 \text { hours of induction. Negative NNTs suggest that the treatment is less } \\
\text { effective than placebo at preventing a failed vaginal delivery within } 24 \text { hours. }\end{array}$} \\
\hline
\end{tabular}


Treatment comparison; control $v$ active treatment

Vaginal prostaglandin $\mathrm{E}_{2}$ tablet $\boldsymbol{v}$

Vaginal prostaglandin $\mathrm{E}_{2}$ gel

Vaginal prostaglandin $E_{2}$ pessary (slow release)

Intracervical prostaglandin $\mathrm{E}_{2}$

Vaginal prostaglandin $E_{2}$ pessary (normal release)

Vaginal misoprostol (dose $<50 \mu \mathrm{g})$

Vaginal misoprostol (dose $\geq 50 \mu \mathrm{g}$ )

Oral misoprostol tablet (dose $<50 \mu \mathrm{g}$ )

Oral misoprostol tablet (dose $\geq 50 \mu \mathrm{g}$ )

Titrated (low dose) oral misoprostol solution

Vaginal misoprostol pessary (sustained release)

Vaginal prostaglandin $\mathrm{E}_{\mathbf{2}}$ (gel) $v$

Vaginal prostaglandin $E_{2}$ pessary (slow release)

Intracervical prostaglandin $E_{2}$

Vaginal prostaglandin $\mathrm{E}_{2}$ pessary (normal release)

Vaginal misoprostol (dose $<50 \mu \mathrm{g}$ )

Vaginal misoprostol (dose $\geq 50 \mu \mathrm{g}$ )

Oral misoprostol tablet (dose $<50 \mu \mathrm{g})$

Oral misoprostol tablet (dose $\geq 50 \mu \mathrm{g}$ )

Titrated (low dose) oral misoprostol solution

Vaginal misoprostol pessary (sustained release)

Vaginal prostaglandin $\mathrm{E}_{2}$ pessary (slow release) $v$ Intracervical prostaglandin $E_{2}$

Vaginal prostaglandin $E_{2}$ pessary (normal release)

Vaginal misoprostol (dose $<50 \mu \mathrm{g}$ )

Vaginal misoprostol (dose $\geq 50 \mu \mathrm{g}$ )

Oral misoprostol tablet (dose $<50 \mu \mathrm{g})$

Oral misoprostol tablet (dose $\geq 50 \mu \mathrm{g}$ )

Titrated (low dose) oral misoprostol solution

Vaginal misoprostol pessary (sustained release)

Intracervical prostaglandin $\mathrm{E}_{\mathbf{2}} \boldsymbol{v}$

Vaginal prostaglandin $E_{2}$ pessary (normal release)

Vaginal misoprostol (dose $<50 \mu \mathrm{g})$

Vaginal misoprostol (dose $\geq 50 \mu \mathrm{g}$ )

Oral misoprostol tablet (dose $<50 \mu \mathrm{g}$ )

Oral misoprostol tablet (dose $\geq 50 \mu \mathrm{g}$ )

Titrated (low dose) oral misoprostol solution

Vaginal misoprostol pessary (sustained release)

Vaginal prostaglandin $\mathrm{E}_{2}$ pessary (normal release) $v$

Vaginal misoprostol (dose $<50 \mu \mathrm{g})$

Vaginal misoprostol (dose $\geq 50 \mu \mathrm{g}$ )

Oral misoprostol tablet (dose $<50 \mu \mathrm{g}$ )

Oral misoprostol tablet (dose $\geq 50 \mu \mathrm{g}$ )

Titrated (low dose) oral misoprostol solution

Vaginal misoprostol pessary (sustained release)

Vaginal misoprostol (dose $<50 \mu \mathrm{g}) v$

Vaginal misoprostol (dose $\geq 50 \mu \mathrm{g}$ )

Oral misoprostol tablet (dose $<50 \mu \mathrm{g}$ )

Oral misoprostol tablet (dose $\geq 50 \mu \mathrm{g}$ )

Titrated (low dose) oral misoprostol solution

Vaginal misoprostol pessary (sustained release)

Vaginal misoprostol (dose $\geq 50 \mu \mathrm{g}) v$

Oral misoprostol tablet (dose $<50 \mu \mathrm{g}$ )

Oral misoprostol tablet (dose $\geq 50 \mu \mathrm{g}$ )

Titrated (low dose) oral misoprostol solution

Vaginal misoprostol pessary (sustained release)

Oral misoprostol tablet (dose $<50 \mu \mathrm{g}) v$

Oral misoprostol tablet (dose $\geq 50 \mu \mathrm{g}$ )

Titrated (low dose) oral misoprostol solution

Vaginal misoprostol pessary (sustained release)

Oral misoprostol tablet (dose $\geq \mathbf{5 0} \boldsymbol{\mu g}$ ) $v$

Titrated (low dose) oral misoprostol solution

Vaginal misoprostol pessary (sustained release)

Titrated (low dose) oral misoprostol solution $v$

Vaginal misoprostol pessary (sustained release)

0.1
Odds ratio

(95\% credible interval)

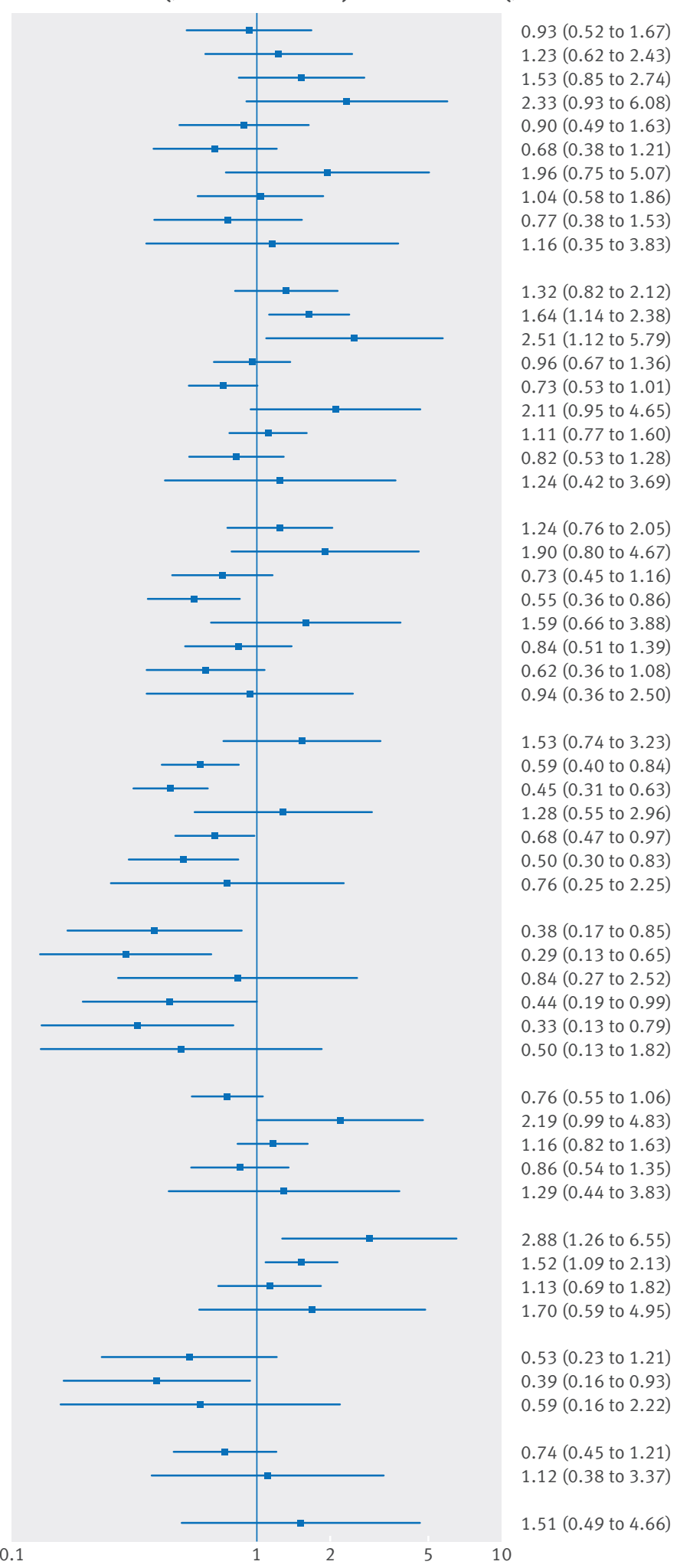

Fig 3 | Odds ratios and 95\% credible intervals from network meta-analysis of failure to achieve vaginal delivery within 24 hours. An odds ratio > 1 favours control (that is, fewer events occur with control than with active treatment), while an odds ratio < 1 favours the active treatment (fewer undesirable events occurred with the active treatment) 

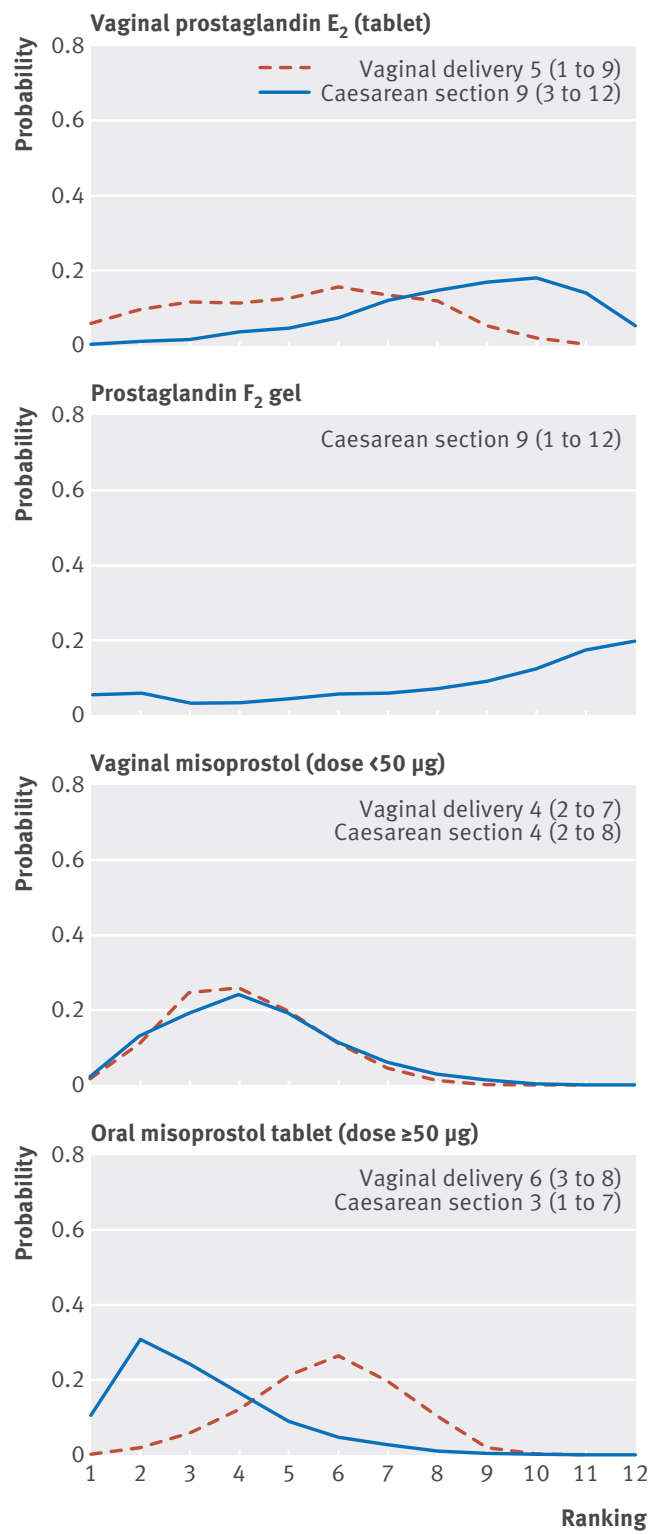

Vaginal prostaglandin $E_{2}$ (gel)

Vaginal delivery 4 (2 to 8 ) Caesarean section 6 ( 3 to 9 )

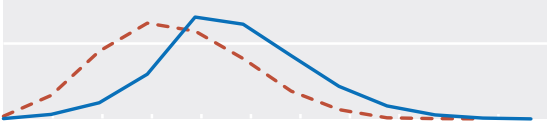

Intracervical prostaglandin $\mathrm{E}_{2}$

Vaginal delivery 9 (7 to 10$)$ Caesarean section 7 ( 4 to 10$)$

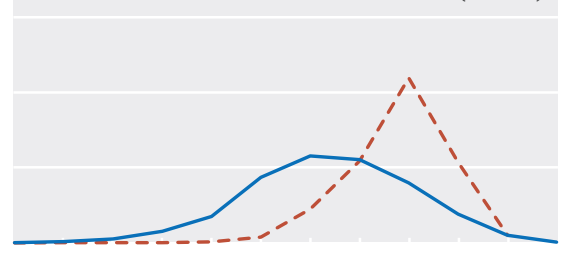

Vaginal misoprostol (dose $\geq 50 \mu$ g)

Vaginal delivery 1 ( 1 to 4$)$ Caesarean section 3 (1 to 7 )

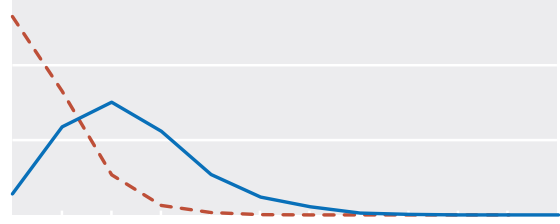

Titrated (low dose) oral misoprostol solution

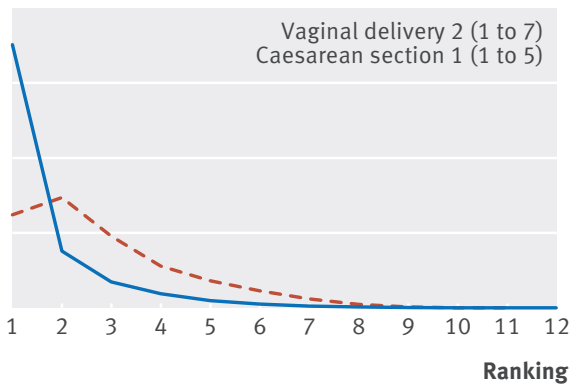

Vaginal prostaglandin $E_{2}$ pessary (slow release)

Vaginal delivery 7 (3 to 10 ) Caesarean section 8 (2 to 11 )

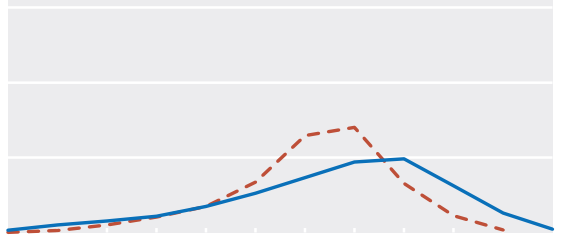

Vaginal prostaglandin $E_{2}$ pessary (normal release)

Vaginal delivery 11 (6 to 11$)$ Caesarean section 10 (3 to 12 )

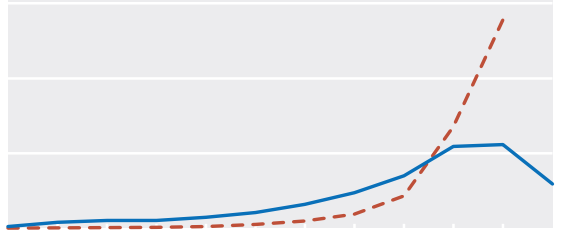

Oral misoprostol tablet (dose $<50 \mu \mathrm{g})$

Vaginal delivery 10 (4 to 11 ) Caesarean section 11 (3 to 12 )

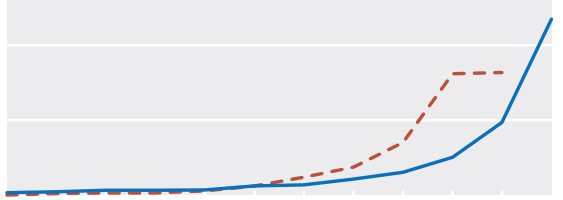

Sustained release misoprostol pessary

Vaginal delivery 7 (1 to 11$)$ Caesarean section 9 (1 to 12 )

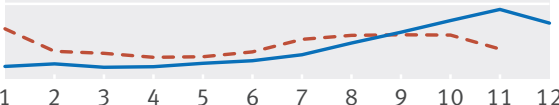

Ranking

Fig 4 | Ranking for each of the 12 prostaglandin treatments for vaginal delivery not achieved within 24 hours and caesarean section. Ranking indicates the probability of being the best treatment, the second best, the third best, etc. For comparability across outcomes, rankings are based on the sensitivity analysis having excluded studies at high risk of bias

included). We note that the results are not materially different between the full network (269 trials) and the sensitivity analysis network (160 trials).

Table 2 reports the posterior median odds ratios (95\% credible intervals) for each treatment relative to placebo (the full results are reported in appendix 6, table 5). We note that, for all but vaginal prostaglandin $\mathrm{E}_{2}$ tablet versus placebo (Table 2), the direct and network meta-analysis results are similar. However, this is consistent with chance (from 49 statistical tests we might expect 2.5 to be significant by chance), and we did not observe any meaningful difference in residual deviance or deviance information criterion values between the inconsistency and consistency models for caesarean section (appendix 6 , table 8). Relative to the size of the treatment effect estimates, between-trial heterogeneity was observed for this outcome ( $\tau=0.09$ (95\% credible interval 0.003 to 0.22$)$ ).
When active treatments were compared, six out of 66 comparisons reached the conventional level of statistical significance (fig 5). With placebo used as the reference (Table 2), five active treatment regimens resulted in significant reduction in caesarean section, namely vaginal prostaglandin $\mathrm{E}_{2}$ (gel), vaginal misoprostol tablet $<50 \mu \mathrm{g}$, vaginal misoprostol tablet $\geq 50 \mu \mathrm{g}$, oral misoprostol tablet $\geq 50 \mu \mathrm{g}$, and titrated (low dose) oral misoprostol solution.

The safest treatment in terms of caesarean section risk was titrated (low dose) oral misoprostol solution, with a $70 \%$ probability of being the best and with the best (lowest) median ranking (fig 4). The absolute probability of an event for titrated oral misoprostol was 15\% (95\% credible interval 3\% to $40 \%$ ). The probability of being ranked in the top three treatments was $92 \%$ for titrated (low dose) oral misoprostol solution and 66\% 


\begin{tabular}{|c|c|c|c|c|}
\hline Treatment comparison & $\begin{array}{l}\text { Direct comparison } \\
\text { Odds ratio } \\
(95 \% \mathrm{Crl})^{*}\end{array}$ & \multicolumn{3}{|c|}{ Network meta-analysis } \\
\hline Placebo & Reference & Reference & Reference & $0.21(0.05$ to 0.50$)$ \\
\hline Vaginal prostaglandin $\mathrm{E}_{2}$ (tablet) & $0(0$ to 0.69$)$ & $0.93(0.70$ to 1.23$)$ & $37(-682$ to 722$)$ & 0.20 (0.04 to 0.49$)$ \\
\hline Vaginal prostaglandin $\mathrm{E}_{2}$ (gel) & 0.89 (0.68 to 1.18$)$ & $0.80(0.68$ to 0.95$)$ & 35 (13 to 182$)$ & $0.18(0.04$ to 0.45$)$ \\
\hline Vaginal prostaglandin $\mathrm{E}_{2}$ pessary (slow release) & $0.56(0.25$ to 1.19$)$ & 0.89 (0.67 to 1.15$)$ & $40(-547$ to 621$)$ & 0.19 (0.04 to 0.48$)$ \\
\hline Prostaglandin $\mathrm{F}_{2}$ gel & 0.67 (0.24 to 1.89$)$ & 0.98 (0.57 to 1.59) & $17(-503$ to 491$)$ & $0.20(0.04$ to 0.51$)$ \\
\hline Intracervical prostaglandin E2 & $0.85(0.66$ to 1.1$)$ & $0.86(0.72$ to 1.02$)$ & $47(-167$ to 389$)$ & $0.19(0.04$ to 0.47$)$ \\
\hline Oral misoprostol tablet $(<50 \mu \mathrm{g})$ & - & $1.17(0.70$ to 1.85$)$ & $-17(-488$ to 450$)$ & $0.23(0.05$ to 0.55$)$ \\
\hline Oral misoprostol tablet $(\geq 50 \mu \mathrm{g})$ & $0.59(0.36$ to 0.95$)$ & 0.72 (0.59 to 0.89) & 24 (10 to 102) & $0.16(0.03$ to 0.43$)$ \\
\hline Titrated oral misoprostol solution $(<50 \mu \mathrm{g})$ & - & $0.65(0.49$ to 0.83$)$ & $18(8$ to 75$)$ & $0.15(0.03$ to 0.40$)$ \\
\hline Misoprostol vaginal pessary sustained release & - & 0.97 (0.61 to 1.48) & $21(-565$ to 615$)$ & $0.20(0.04$ to 0.50$)$ \\
\hline \multicolumn{5}{|c|}{$\begin{array}{l}95 \% \mathrm{Crl}=95 \% \text { credible interval. NNT = number needed to treat. } \\
\text { *An odds ratio }>1 \text { favours placebo (that is, fewer events occur with placebo than with active treatment), whereas an odds ratio <1 favours active } \\
\text { treatment (fewer undesirable events occur with active treatment). Empty cells indicate that no direct evidence was available for that comparison. } \\
\text { tNNTs were calculated based on the absolute odds of an event on the reference treatment. Positive NNTs are interpreted as the number of women } \\
\text { needed to be treated to prevent one caesarean section. Negative NNTs suggest that the treatment is less effective than placebo at preventing a } \\
\text { caesarean section. }\end{array}$} \\
\hline
\end{tabular}

for oral misoprostol tablet $\geq 50 \mu \mathrm{g}$. All other treatments had a lower probability of being among the top three. The probability of being ranked in the bottom three (poorest in terms of risk of caesarean section) was 56\% for vaginal prostaglandin $\mathrm{E}_{2}$ pessary (normal release) and $77 \%$ for oral misoprostol tablet $<50 \mu \mathrm{g}$.

\section{Uterine hyperstimulation with fetal heart changes}

After the exclusion of trials with zero or $100 \%$ events in all arms, 129 trials assessed the outcome of uterine hyperstimulation. Model fit statistics indicated evidence of inconsistency for this network (appendix 6, table 9). A pre-specified sensitivity analysis examining the effect of removing trials at high risk of bias from the network and subgroup analyses exploring inclusionexclusion criteria for previous caesarean section, membrane status, and gestational length did not explain the observed inconsistency. Consequently, we were not able to report robust network meta-analysis estimates or ranking for this outcome (appendix 6, table 6). The results from the direct head-to-head meta-analyses are reported in appendix 6 , table 6 . We note that, of 25 active versus active treatment comparisons, only two achieved conventional statistical significance. Compared with intracervical prostaglandin $\mathrm{E}_{2}$, vaginal misoprostol $\geq 50 \mu \mathrm{g}$ was associated with a fourfold increase in the odds of uterine hyperstimulation (odds ratio 3.57 (95\% credible interval 1.66 to 8.06)). Similarly, vaginal misoprostol $\geq 50 \mu \mathrm{g}$ was associated with a near threefold increase in the odds of hyperstimulation compared with slow release vaginal prostaglandin $\mathrm{E}_{2}$ (odds ratio 2.73 (1.08 to 7.40$)$ )

\section{Mortality and severe morbidity}

Neonatal and maternal mortality and serious morbidity outcomes were too rare or poorly reported to carry out meaningful analysis even with a continuity correction of 0.5 added to each cell (see appendix 6, tables 10-14). Given the lack of universally accepted definitions of serious infant or maternal morbidity we planned to include any reported by individual trials. However, even when defined in such a way, they were rarely reported. For this reason, the data included in the analysis are for perinatal and maternal death only. Fifty one of the 280 included trials $(18.2 \%)$ reported perinatal deaths with an incidence of $0.2 \%$ (30/14367). Eighteen out of 280 trials $(6 \%)$ reported a total of four maternal deaths.

\section{Subgroup and sensitivity analyses}

The full details of the subgroup analyses are reported in appendix 6 (table 15). Our findings were robust when we removed studies with placebo and no-treatment arms from the analyses. With regards to median ranking, titrated (low dose) oral misoprostol solution was still the highest ranking active treatment for caesarean section. For achieving vaginal delivery within 24 hours, vaginal misoprostol $\geq 50 \mu \mathrm{g}$ was still the highest ranked treatment, with titrated low does oral misoprostol solution ranked second (based on median ranks).

For each outcome, we examined the distribution of potential effect modifiers by comparing the proportion of trials containing each of the pre-specified characteristics (appendix 6, tables 1-3). For the outcome of caesarean section, previous caesarean section as an inclusion-exclusion criterion seemed unevenly distributed; all trials with a titrated low dose oral misoprostol solution arm had excluded women with a previous caesarean section, as did both trials with a sustained release misoprostol vaginal pessary arm. In contrast, only $31 \%$ of trials with an intracervical prostaglandin $\mathrm{E}_{2}$ arm (31/99) and only $48 \%$ of trials with a vaginal 
Treatment comparison; control $v$ active treatment

Vaginal prostaglandin $\mathrm{E}_{2}$ tablet $\boldsymbol{v}$

Vaginal prostaglandin $\mathrm{E}_{2}$ (gel)

Vaginal prostaglandin $\mathrm{E}_{2}$ pessary (slow release) Prostaglandin $\mathrm{F}_{2}$ gel

Intracervical prostaglandin $\mathrm{E}_{2}$

Vaginal prostaglandin $E_{2}$ pessary (normal release) Vaginal misoprostol (dose $<50 \mu \mathrm{g}$ )

Vaginal misoprostol (dose $\geq 50 \mu \mathrm{g}$ )

Oral misoprostol tablet (dose $<50 \mu \mathrm{g})$

Oral misoprostol tablet (dose $\geq 50 \mu \mathrm{g})$

Titrated (low dose) oral misoprostol solution

Vaginal misoprostol pessary (sustained release)

Vaginal prostaglandin $\mathrm{E}_{2}$ (gel) $v$

Vaginal prostaglandin $\mathrm{E}_{2}$ pessary (slow release) Prostaglandin $\mathrm{F}_{2}$ gel

Intracervical prostaglandin $\mathrm{E}_{2}$

Vaginal prostaglandin $\mathrm{E}_{2}$ pessary (normal release) Vaginal misoprostol (dose $<50 \mu \mathrm{g}$ )

Vaginal misoprostol (dose $\geq 50 \mu \mathrm{g})$

Oral misoprostol tablet (dose $<50 \mu \mathrm{g})$

Oral misoprostol tablet (dose $\geq 50 \mu \mathrm{g})$

Titrated (low dose) oral misoprostol solution

Vaginal misoprostol pessary (sustained release)

Vaginal prostaglandin $\mathrm{E}_{2}$ pessary (slow release) $v$ Prostaglandin $\mathrm{F}_{2}$ gel

Intracervical prostaglandin $\mathrm{E}_{2}$

Vaginal prostaglandin $\mathrm{E}_{2}$ pessary (normal release) Vaginal misoprostol (dose $<50 \mu \mathrm{g})$

Vaginal misoprostol (dose $\geq 50 \mu \mathrm{g}$ )

Oral misoprostol tablet (dose $<50 \mu \mathrm{g})$

Oral misoprostol tablet (dose $\geq 50 \mu \mathrm{g})$

Titrated (low dose) oral misoprostol solution

Vaginal misoprostol pessary (sustained release)

Prostaglandin $\mathrm{F}_{2}$ gel $v$

Intracervical prostaglandin $\mathrm{E}_{2}$

Vaginal prostaglandin $\mathrm{E}_{2}$ pessary (normal release)

Vaginal misoprostol (dose $<50 \mu \mathrm{g}$ )

Vaginal misoprostol (dose $\geq 50 \mu \mathrm{g}$ )

Oral misoprostol tablet (dose $<50 \mu \mathrm{g})$

Oral misoprostol tablet (dose $\geq 50 \mu \mathrm{g}$ )

Titrated (low dose) oral misoprostol solution

Vaginal misoprostol pessary (sustained release)

Intracervical prostaglandin $\mathrm{E}_{2} \boldsymbol{V}$

Vaginal prostaglandin $E_{2}$ pessary (normal release) Vaginal misoprostol (dose $<50 \mu \mathrm{g})$

Vaginal misoprostol (dose $\geq 50 \mu \mathrm{g}$ )

Oral misoprostol tablet (dose $<50 \mu \mathrm{g}$ )

Oral misoprostol tablet (dose $\geq 50 \mu \mathrm{g})$

Titrated (low dose) oral misoprostol solution

Vaginal misoprostol pessary (sustained release)

Vaginal prostaglandin $\mathrm{E}_{2}$ pessary (normal release) $v$ Vaginal misoprostol (dose $<50 \mu \mathrm{g}$ )

Vaginal misoprostol (dose $\geq 50 \mu \mathrm{g}$ )

Oral misoprostol tablet (dose $<50 \mu \mathrm{g}$ )

Oral misoprostol tablet (dose $\geq 50 \mu \mathrm{g})$

Titrated (low dose) oral misoprostol solution

Vaginal misoprostol pessary (sustained release)

Vaginal misoprostol (dose $<50 \mu \mathrm{g}) v$

Vaginal misoprostol (dose $\geq 50 \mu \mathrm{g}$ )

Oral misoprostol tablet (dose $<50 \mu \mathrm{g}$ )

Oral misoprostol tablet (dose $\geq 50 \mu \mathrm{g}$ )

Titrated (low dose) oral misoprostol solution

Vaginal misoprostol pessary (sustained release)

Vaginal misoprostol (dose $\geq 50 \mu g) v$

Oral misoprostol tablet (dose $<50 \mu \mathrm{g})$

Oral misoprostol tablet (dose $\geq 50 \mu \mathrm{g})$

Titrated (low dose) oral misoprostol solution

Vaginal misoprostol pessary (sustained release)

Oral misoprostol tablet (dose $<50 \mu \mathrm{g}) v$

Oral misoprostol tablet (dose $\geq 50 \mu \mathrm{g}$ )

Titrated (low dose) oral misoprostol solution

Vaginal misoprostol pessary (sustained release)

Oral misoprostol tablet (dose $\geq 50 \mu \mathrm{g}) v$

Titrated (low dose) oral misoprostol solution

Vaginal misoprostol pessary (sustained release)

Titrated (low dose) oral misoprostol solution $v$

Vaginal misoprostol pessary (sustained release)

0.4
Odds ratio

(95\% credible interval)

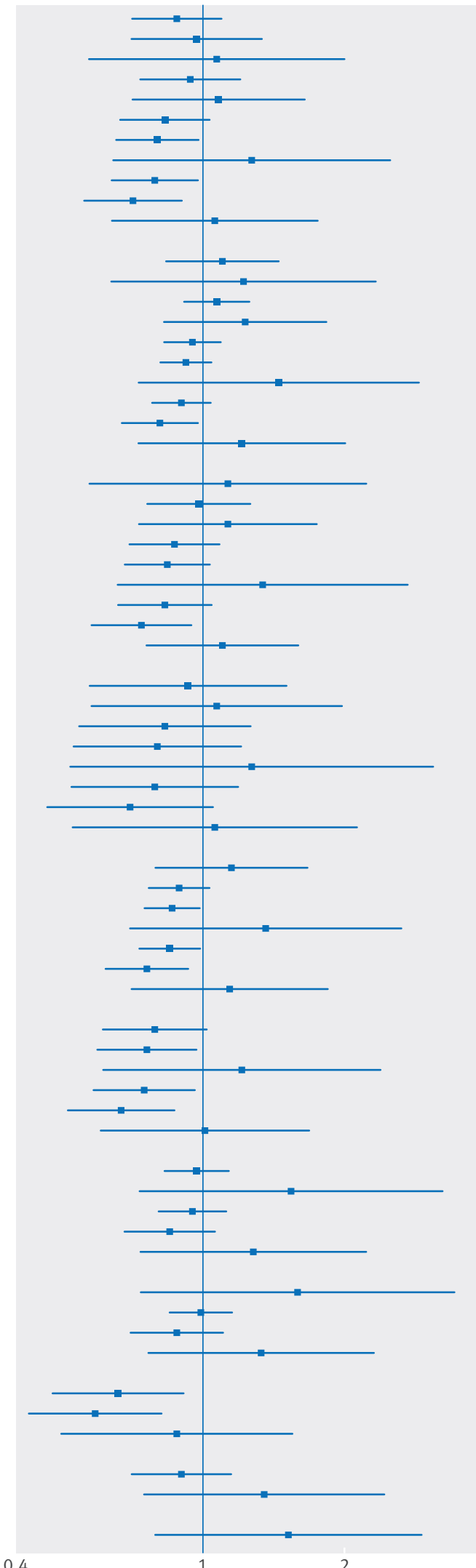

Odds ratio

(95\% credible interval)

0.88 (0.68 to 1.12$)$

$0.97(0.68$ to 1.33$)$

1.07 (0.58 to 1.80$)$

$0.94(0.71$ to 1.21$)$

$1.08(0.71$ to 1.56$)$

0.83 (0.63 to 1.08$)$

0.80 (0.62 to 1.02$)$

1.27 (0.73 to 2.07$)$

0.79 (0.59 to 1.03$)$

$0.71(0.51$ to 0.96$)$

1.06 (0.63 to 1.66$)$

$1.10(0.86$ to 1.40$)$

1.22 (0.72 to 1.96$)$

$1.07(0.91$ to 1.24$)$

1.23 (0.88 to 1.66$)$

0.95 (0.81 to 1.10$)$

0.92 (0.79 to 1.05$)$

1.45 (0.89 to 2.25$)$

0.90 (0.76 to 1.06$)$

0.81 (0.65 to 0.99 )

1.21 (0.77 to 1.81 )

$1.13(0.63$ to 1.87$)$

$0.98(0.75$ to 1.26$)$

1.13 (0.76 to 1.61$)$

0.87 (0.67 to 1.12 )

0.84 (0.66 to 1.06 )

1.34 (0.77 to 2.16$)$

0.83 (0.63 to 1.07 )

0.74 (0.54 to 0.99 )

$1.10(0.77$ to 1.53$)$

0.93 (0.54 to 1.49$)$

1.07 (0.58 to 1.78 )

0.83 (0.48 to 1.34$)$

0.80 (0.47 to 1.28$)$

1.27 (0.60 to 2.35$)$

0.79 (0.45 to 1.29$)$

$0.70(0.40$ to 1.14$)$

$1.06(0.52$ to 1.91$)$

1.15 (0.83 to 1.54$)$

0.89 (0.75 to 1.05$)$

0.86 (0.73 to 1.01$)$

$1.36(0.82$ to 2.13$)$

0.85 (0.70 to 1.01 )

0.76 (0.59 to 0.96$)$

$1.14(0.72$ to 1.71$)$

0.79 (0.56 to 1.09$)$

0.76 (0.55 to 1.04$)$

1.21 (0.68 to 2.01 )

0.75 (0.53 to 1.05 )

0.67 (0.46 to 0.95$)$

1.01 (0.59 to 1.63 )

0.97 (0.82 to 1.13$)$

1.54 (0.93 to 2.38)

0.95 (0.80 to 1.12$)$

0.85 (0.67 to 1.07 )

1.28 (0.91 to 1.92$)$

1.59 (0.96 to 2.49)

0.99 (0.84 to 1.15$)$

0.88 (0.69 to 1.11$)$

1.33 (0.85 to 1.97$)$

$0.66(0.39$ to 1.02$)$

0.59 (0.34 to 0.93$)$

0.88 (0.45 to 1.55 )

$0.90(0.70$ to 1.14$)$

1.35 (0.85 to 2.04 )

1.52 (0.93 to 2.35$)$

Fig 5 | Odds ratios and $95 \%$ credible intervals from network meta-analysis of caesarean section. An odds ratio $>1$ favours control (that is, fewer events occur with control than with active treatment), while an odds ratio $<1$ favours the active treatment (fewer undesirable events occurred with the active treatment) 
prostaglandin $\mathrm{E}_{2}$ pessary (normal release) arm excluded women with a previous caesarean section (appendix 6, table 2). A similar distribution of characteristics was observed for failure to achieve vaginal delivery within 24 hours (appendix 6, table 1).

It is possible that these differences were partly due to poor reporting (that is, inclusion and exclusion criteria were not always well reported). Nevertheless, subgroup analyses were conducted for both vaginal delivery and caesarean section outcomes, in which we removed trials which had randomized women with previous caesarean section (either all or some participants). The findings were robust when these trials were removed from the analyses, with titrated (low dose) oral misoprostol solution still being the highest ranking treatment for the outcome of caesarean section, and vaginal misoprostol $\geq 50 \mu \mathrm{g}$ remaining the highest ranking treatment for achieving vaginal delivery within 24 hours (see appendix 6, table 15). The one noticeable change in results was the median rank of oral misoprostol tablet $<50 \mu \mathrm{g}$, which increased from 11 for the outcome of caesarean section to 4 when trials in which some women who had previously had a caesarean section were removed.

\section{Discussion}

Principal findings

Network meta-analysis provides a unique opportunity to rank prostaglandin treatments in a coherent, methodologically robust manner, and allows comparisons to be made across outcomes (figs 3-5), to help guide clinicians and patients to make informed treatment choices. This network meta-analysis showed that misoprostol is likely to be superior to dinoprostone (prostaglandin $\mathrm{E}_{2}$ ) for labour induction. On balance, if treatment rankings for vaginal delivery within 24 hours and caesarean section were informally combined, oral misoprostol solution $<50 \mu \mathrm{g}$ would seem the most highly ranked treatment across the two outcomes, followed by high dose misoprostol vaginal tablets and then low dose vaginal misoprostol tablets. However, the width of the credible intervals around the posterior median ranks was considerable, and so we urge caution in the interpretation of rankings and the probability that treatments are "best." In particular, we note the uncertainty around sustained release vaginal misoprostol: there was insufficient evidence to draw conclusions about its relative safety and efficacy compared with vaginal tablets, which have been examined in a larger number of trials (and are estimated with greater certainty).

\section{Strengths and limitations of the study}

We have made a considerable effort to include all relevant randomised controlled trials with no language or setting restrictions: 280 studies with data for 48068 women were included in the systematic review, which is a particular strength of this study. We have started from the premise that all 12 treatment regimens would be suitable for all included women. This underlying assumption of "transitivity" is critically important for the network meta-analysis. To evaluate this, we extracted the data for six potential treatment modifiers (previous caesarean section, parity, status of amniotic membranes, Bishop score, gestational age, and singleton or multiple pregnancy) and found no clinically important differences between the 12 regimens (appendix 6, tables 1-3). We took the view that the trial's setting was not likely to be a critical treatment modifier because in the included trials intrapartum fetal monitoring and immediate access to caesarean section were available to most women. As this may not be the case in low resource settings, the findings from our analysis are more likely to be applicable to high resource settings.

In terms of efficacy, we focused on the ability of prostaglandins to result in vaginal delivery within 24 hours. This definition of efficacy may be seen as controversial given that cervical ripening is often regarded as a distinctly different process from induction of labour. ${ }^{1}$ This view is reflected by the fact that cervical changes measured by the Bishop score are often the main measure of efficacy in included randomised trials. We argue that both women and clinicians view cervical ripening and labour induction as a seamless process, with the main aim being to achieve safe vaginal birth of a healthy baby in the shortest time possible. In this respect, misoprostol seems to be superior to other prostaglandins.

We anticipated that serious maternal and neonatal adverse events would be rare in cohorts of women recruited to randomised trials of labour induction. It was, nevertheless, disappointing how infrequently mortality and serious morbidity were adequately reported. We note that only 51 out of 280 trials reported that they had assessed perinatal death, and only 18 reported assessing maternal death (appendix 6). Where these outcomes were reported, they were rare: 30 out of 51 trials reporting perinatal death and 14 out of 18 trials that reported maternal death did not observe events in either arm of the trial. Assessment of safety was, therefore, limited to caesarean section. All prostaglandins, misoprostol in particular, even in low doses, are known to cause uterine rupture with possible catastrophic consequences, particularly in women with previous caesarean section. ${ }^{31}$ The efficacy of both high and low dose vaginal misoprostol has to be seen in this context.

In order to form a judgment of which prostaglandin is most effective, we could have formally combined the outcomes vaginal delivery within 24 hours and caesarean section. However, to do so would assume that each outcome is of equal importance. Outcomes are rarely of equal importance, particularly when efficacy and safety data are combined. A more rigorous approach to obtain a single overall summary would be to identify utility weights for the different outcomes to provide a weighted average. The expected utility gain could then be compared with the expected costs of the treatments in a cost-effectiveness analysis. This is an area for further work.

We had intended to include uterine hyperstimulation in our network meta-analysis. Unfortunately, results relating to uterine hyperstimulation were not always reported, and, when they were, hyperstimulation was defined inconsistently or not all. These issues are likely 
to have contributed to the difficulties in model fitting and statistical inconsistency observed for this outcome. In practice, caesarean section and uterine hyperstimulation are clearly related-one would expect that clinically persistent, clinically important uterine hyperstimulation will eventually result in caesarean section.

\section{Conclusions and implications for practice}

The best safety profile of low dose misoprostol solution with reasonable efficacy (median rank 2) may have important implications for clinical practice. It is noteworthy that this method is currently not recommended by the World Health Organization, ${ }^{32}$ while low dose $(25 \mu \mathrm{g})$ oral tablets every 2 hours are recommended despite the worst overall ranking in our network meta-analysis. ${ }^{4}$ In clinical situations where less frequent vaginal administration of misoprostol may be preferable, particularly in settings with intensive monitoring facilities, $50 \mu \mathrm{g}$ vaginal misoprostol tablets may be a reasonable treatment of choice. Most of the studies in our network meta-analysis used 4 hourly treatment regimens, and some opted for less frequent administration (6 hourly).

Overall, misoprostol may be the best prostaglandin for labour induction, as titrated low dose oral solution seems to be the safest in terms of caesarean section risk, while vaginal misoprostol tablets $(\geq 50 \mu \mathrm{g})$ are the most effective in achieving vaginal delivery within 24 hours of induction. These findings have important implications for national and international guidelines for induction of labour and future research in this area.

We thank Lynn Hampson, Helen West, and Nancy Medley, Cochrane Pregnancy and Childbirth Group, for their support in preparing the final draft of this paper.

Contributors: ZA and DMC conceived and designed the original study, and are the study guarantors. ZA contributed to planning the review and network meta-analysis, data interpretation and writing the report. EK conducted the statistical analyses and revised the paper. TD contributed to planning the review, data collection, quality assessment, and writing the report. NJW supervised the statistical analyses and drafted and revised the manuscript. SD contributed to and supervised the statistical analyses and revised the manuscript. LVJ contributed to data collection, quality assessment, and writing the report. KN contributed to data collection and quality assessment and commented on the report. DMC conducted and supervised the statistical analyses and drafted and revised the manuscript.

Funding: The work was supported in part by National Institute for Health Research, UK, HTA project 12/126/17 (www.netscc.ac.uk). The views and opinions expressed therein are those of the authors and do not necessarily reflect those of the NIHR, NHS, or Department of Health. DMC is supported by an MRC Population Health Scientist postdoctoral fellowship (G0902118). The funders had no role in study design, data collection and analysis, decision to publish, or preparation of the manuscript.

Competing interests: All authors have completed the ICMJE uniform disclosure form at www.icmje.org/coi_disclosure.pdf (available on request from the corresponding author) and declare: support from NIHR for the submitted work; no financial relationships with any organisations that might have an interest in the submitted work in the previous three years; no other relationships or activities that could appear to have influenced the submitted work.

Data sharing: All data and statistical code are available in the appendices provided by the authors

Transparency: The manuscript's guarantors affirm that the manuscript is an honest, accurate, and transparent account of the study being reported; that no important aspects of the study have been omitted; and that any discrepancies from the study as planned (and, if relevant, registered) have been explained.

This is an Open Access article distributed in accordance with the Creative Commons Attribution Non Commercial (CC BY-NC 4.0) license, which permits others to distribute, remix, adapt, build upon this work non-commercially, and license their derivative works on different terms, provided the original work is properly cited and the use is noncommercial. See: http://creativecommons.org/licenses/by-nc/4.0/.

1 American College of Obstetricians and Gynecologists. ACOG practice bulletin. Clinical Management Guidelines for ObstetricianGynecologists. No. 107. Induction of Labor. Obstet Gynecol 2009;114:386-97.

2 Chauhan SP, Ananth CV. Induction of labor in the United States: a critical appraisal of appropriateness and reducibility. Semin Perinatol 2012:36:336-43.

3 National Institute for Health and Care Excellence. Induction of labour. (Clinical guideline 70). NICE, 2008. www.nice.org.uk/ guidance/cg70.

4 Tang J, Kapp N, Dragoman M, de Souza JP. WHO recommendations for misoprostol use for obstetric and gynecologic indications. Int J Gynaecol Obstet 2013;121:186-9.

5 Austin SC, Sanchez-Ramos L, Adair CD. Labor induction with intravaginal misoprostol compared with the dinoprostone vaginal insert: a systematic review and metaanalysis. Am J Obstet Gynecol 2010;202:624.e1-9.

6 Facchinetti F, Fontanesi F, Del Giovane C. Pre-induction of labour: comparing dinoprostone vaginal insert to repeated prostaglandin administration: a systematic review and meta-analysis. J Matern Fetal Neonatal Med 2012:25:1965-9.

7 Mozurkewich EL, Chilimigras JL, Berman DR, Perni UC, Romero VC, King VJ, et al. Methods of induction of labour: a systematic review. BMC Pregnancy Childbirth 2011:11:84.

8 Caldwell DM, Ades AE, Higgins JPT. Simultaneous comparison of multiple treatments: combining direct and indirect evidence. BM/ 2005:331:879-900.

9 Lee AW. Review of mixed treatment comparisons in published systematic reviews shows marked increase since 2009 I Clin Epidemiol 2014;67:138-43.

10 Higgins JPT, Whitehead A. Borrowing strength from external trials in a meta-analysis. Stat Med 1996;15:2733-49.

11 Lu G, Ades AE. Combination of direct and indirect evidence in mixed treatment comparisons. Stat Med 2004;23:3105-24.

12 Wells GA, Sultan SA, Chen L, Khan M, Coyle D. Indirect evidence: indirect treatment comparisons in meta-analysis. Canadian Agency for Drugs and Technologies in Health, 2009.

13 National Institute for Health and Care Excellence. Guide to the methods of technology appraisal. NICE, 2008. www.nice.nhs.uk/aboutnice/ howwework/devnicetech/GuideToMethodsTechnologyAppraisal2008. jsp.

14 Cochrane Collaboration. Comparing Multiple Interventions Methods Group. Comparing multiple interventions in Cochrane reviews. 2014. http:// cmimg.cochrane.org/comparing-multiple-interventions-cochrane-reviews.

15 Haas DM, Caldwell DM, Kirkpatrick P, McIntosh IJ, Welton NJ. Tocolytic therapy for preterm delivery: systematic review and network meta-analysis. BMJ 2012;345:e6226

16 Stettler C, Wandel S, Allemann S, Kastrati A, Morice MC, Schömig A et al. Outcomes associated with drug-eluting and bare-metal stents: a collaborative network meta-analysis. Lancet 2007;370:937-48.

17 Cipriani A, Furukawa TA, Salanti G, Geddes JR, Higgins JPT, Churchill R, et al. Comparative efficacy and acceptability of 12 new-generation antidepressants: a multiple-treatments meta-analysis. Lancet 2009; 373:746-58.

18 Barth J, Munder T, Gerger H, Nüesch E, Trelle S, Znoj H, et al. Comparative efficacy of seven psychotherapeutic interventions for patients with depression: a network meta-analysis. PLOS Med 2013:10:e1001454

19 Singh JA, Christensen R, Wells GA, Suarez-Almazor ME, Buchbinder R, Lopez-Olivo MA, et al. Biologics for rheumatoid arthritis: an overview of Cochrane reviews. Cochrane Database Syst Rev 2009; (4):CD007848.

20 Padwal R, Klarenbach S, Wiebe N, Birch D, Karmali S, Manns B, et al. Bariatric surgery: a systematic review and network meta-analysis of randomized trials. Obesity Rev 2011;12:602-21.

21 Hofmeyr G, Alfirevic Z, Kelly T, Kavanagh I, Thomas J, Brocklehurst P, et al. Methods for cervical ripening and labour induction in later pregnancy: generic protocol [protocol]. Cochrane Database Syst Rev 2000;(2):CD002074.

22 Kelly A, Alfirevic Z, Hofmeyr G, Kavanagh J, Neilson J, Thomas J. Induction of labour in specific clinical situations: generic protoco [protocol]. Cochrane Database Syst Rev 2001;(4):CD003398.

23 Higgins J, Green S, eds. Cochrane handbook for systematic reviews of interventions. Version 5.1.0. Cochrane Collaboration, 2011. www. cochrane-handbook.org; 2011

24 Wood L, Egger M, Gluud LL, Schulz KF, Juni P, Altman DG, et al. Empirical evidence of bias in treatment effect estimates in controlled 
trials with different interventions and outcomes: metaepidemiological study. BMJ 2008;336:601-5.

25 Glenny AM, Altman DG, Song F, Sakarovitch C, Deeks JJ, D'Amico R, et al. Indirect comparisons of competing interventions. Health Technol Assess 2005;9:1-134.

26 OpenBUGS. www.openbugs.net/.

27 Dias S, Ades AE, Sutton AJ, Welton NJ. Evidence synthesis for decision making 2: a generalized linear modeling framework for pairwise and network meta-analysis of randomized controlled trials. Med Decis Making 2013:33:607-17.

28 The BUGS project. DIC: Deviance Information Criterion. How does DIC depend on the parameterisation used? www.mrc-bsu.cam.ac.uk/ software/bugs/the-bugs-project-dic/\#q9.

29 Welton N, Sutton A, Cooper N, Abrams K, Ades A. Evidence synthesis for decision making in healthcare. Wiley, 2012

30 Dias S, Welton NJ, Sutton AJ, Caldwell DM, Lu G, Ades AE. Evidence synthesis for decision making 4: inconsistency in networks of evidence based on randomized controlled trials. Med Decis Making 2013;33:641-56.

31 Wing DA, Lovett K, Paul RH. Disruption of prior uterine incision following misoprostol for labor induction in women with previous cesarean delivery. Obstet Gynecol 1998;91:828-30.

32 World Health Organization. WHO recommendations for induction of labour. WHO, 2011. http://whqlibdoc.who.int/ publications/2011/9789241501156_eng.pdf.

33 Brooks SP, Gelman A. Alternative methods for monitoring convergence of iterative simulations. / Comp Graph Stat 1998; 7:434-55

34 Gelman A, Rubin DB. Inferences from iterative simulation using multiple sequences. Stat Sci 1992:7:457-72.

35 Chaimani A, Higgins JP, Mavridis D, Spyridonos P, Salanti G. Graphica tools for network meta-analysis in STATA. PLOS One 2013;8:e76654.

(c) BMJ Publishing Group Ltd 2015
Appendix 1. Search strategy used to maintain the Cochrane Pregnancy and Childbirth Group's Database of Trials

Appendix 2. List of studies included in network meta-analysis

Appendix 3. List of studies excluded from network meta-analysis

Appendix 4. Description of included studies

Appendix 5. Description of included studies-doses and regimens

Appendix 6. Tables 1-3: Characteristics of trials by treatment and outcome. Tables 4-6: Odds ratios for outcomes with each treatment. Tables 7-9: Model fit and selection statistics by outcome. Tables 10-14: Datafiles used in OpenBUGS analyses for outcomes. Table 15: Posterior median rankings for sensitivity analyses. Table 16: Comparison of risk ratios and odds ratios for vaginal delivery and caesarean section

Appendix 7. Technical appendix

Appendix 8. Inconsistency plots 